\title{
DEVELOPMENT OF COSMETIC CREAM CONTAINING A PHARMACEUTICAL COCRYSTAL OF SALICYLIC AND PHENYLALANINE
}

\author{
HIRIHATTAYA PHETMUNG ${ }^{*}$, SOMCHAI SAWATDEE ${ }^{2,3}$
}

${ }^{1}$ Inorganic and Materials Chemistry Research Unit, Faculty of Science, Thaksin University, Amper Muang, Songkhla 90000, Thailand, ${ }^{2}$ Drug and Cosmetics Excellence Center, Walailak University, Thaiburi, Thasala, Nakhon Si Thammarat, 80161, Thailand, ${ }^{3}$ School of Pharmacy, Walailak University, Thaiburi, Thasala, Nakhon Si Thammarat, 80161, Thailand

Email: tayaphetmung@yahoo.com

Received: 30 Apr 2019, Revised and Accepted: 04 Jul 2019

\begin{abstract}
Objective: The objective of this present work was to develop the chemical peeling cream containing the synthesized active ingredient pharmaceutical cocrystal of salicylic acid and phenylalanine.

Methods: The salicylic acid and phenylalanine cocrystal $\left(\mathrm{H}_{2} \mathrm{Sal} \bullet \mathrm{Phe}\right)$ was synthesized by the solvent evaporation method and characterized by various techniques such as single-crystal X-ray diffraction and Fourier transform infrared spectroscopy. The five formulas of cocrystal cream were prepared. All formulas were then examined and observed for appearance, spreadability, viscosity, pH, homogeneity, SPF test, microbial limit test and stability test.

Results: The $\left(\mathrm{H}_{2} \mathrm{Sal} \bullet \mathrm{Phe}\right)$ consists of no zwitterion phenylalanine for the first time. X-ray crystal structure of cocrystal consists of double $\mathrm{H}_{2} \mathrm{Sal}$ and Phe molecules with stabilized by inter-, intra-molecular and $\pi-\pi$ interactions. By using this cocrystal as an active ingredient for cosmetic development, the chemical peeling cream was produced along with the pharmaceutical examinations. The $\left(\mathrm{H}_{2} \mathrm{Sal} \bullet\right.$ Phe $)$ formulations were prepared $0-1 \%$ and excipients included of jojoba oil, isopropyl myristate, castor oil, glyceryl monostearate cetostearyl alcohol, cyclomethicone (and) dimethicone crosspolymer, vitamin E, white bee's wax, glycerin, PEG 400, xanthan gum, Span 80 and Tween 60. We finally found that the F4 (1\% $\mathrm{H}_{2} \mathrm{Sal} \bullet \mathrm{Phe}$ ) was the best formulation with suitable physical properties of cream and chemical stable after storage. The results of cell viability show $\mathrm{H}_{2} \mathrm{Sal} \bullet \mathrm{Phe}$ is non-toxic with cell.
\end{abstract}

Conclusion: The chemical peeling cream containing ( $\left.\mathrm{H}_{2} \mathrm{Sal} \bullet \mathrm{Phe}\right)$ has shown the promising results which are both safe and efficacious peeling agent. Cocrystal $\left(\mathrm{H}_{2} \mathrm{Sal} \bullet \mathrm{Phe}\right)$ cream can be used as an alternative choice in whitening skin.

Keywords: Pharmaceutical cocrystal, Salicylic acid, Phenylalanine, Cream, Cosmetics, Formulation development

(C) 2019 The Authors. Published by Innovare Academic Sciences Pvt Ltd. This is an open-access article under the CC BY license (http://creativecommons.org/licenses/by/4.0/) DOI: http://dx.doi.org/10.22159/ijap.2019v11i5.33869

\section{INTRODUCTION}

Salicylic acid $\left(\mathrm{H}_{2} \mathrm{Sal}\right)$ is not only a beta-hydroxy acid but also nonsteroidal anti-inflammatory drug (NSAID) [1-3]. It is a hydroxyl derivative of benzoic acid and represents a carboxylic acid attached to aromatic alcohol, phenol [1]. It also is known as skin disorder treatments such as keratolytic properties because of the solubility of intracellular cement. Its lipid solubility permits the interaction with multilamellar structures surrounding the keratinocytes in the stratum corneum and hair follicle, thereby exhibiting follicular atrophy and comedolytic action within the sebaceous unit [1].

Various preparations of salicylic acid have been used for peeling purposes for up to $50 \%$ [4]. The indications of a salicylic acid peeling agent include acne vulgarism, melasma, post-inflammatory hyperpigmentation, freckles, lentigines, mild to moderate of photodamage, texturally roughened skin and fine wrinkle [4]. Marketed salicylic acid does not seem to be effective in exfoliating compared with glycolic acid (8-15\%) that is commercially available and cheaper [5]. Phenylalanine is an essential amino acid which is a building block for proteins in the body [6]. It may be used in cosmetics as well as personal care products, such as topical cream which use to help turn over the pigment-forming melanocytes which are essential in the initiation of pigmentation [1, 6-8]. A chemical peel is used for cosmetics skin improvements [8]. It is known as salicylic acid chemical peels, alpha hydroxy acid (AHA) chemical peels, or glycolic acid peels which is the application of a chemical agent to the skin $[7,8]$. The ingredients and formulation of a light chemical peel, however, depend on the specific patient's skincare needs. With light chemical peels, the chemical solution is left on the skin for a relatively short amount of time. In general, chemical peels can improve the skin's appearance $[1,8,9]$. Pharmaceutical cocrystallization is crystalline molecular complexes containing therapeutic molecules for the development of the active pharmaceutical ingredient (API) drugs [10, 11]. Cocrystals are generally formed through noncovalent interaction bonds (primarily hydrogen bonding), $\pi-\pi$ stacking, van der Waals interactions and other weak interactions [10-12].

In order to improve the physicochemical properties of APIs, pharmaceutical cocrystals can be used as an alternative approach to enhancing specific physical properties of pharmaceutical ingredients [13-15]. Cocrystals of salicylic acid with other organic compounds have been reported for many applications for examples: to develop thermal methods [16], searching for marketing drugs [3], treatment melisma [17]. The cocrystals of salicylic derivatives with amino acid have also been reported in many pharmaceutical applications too [7].

To the best of our knowledge, there are only two reports on the cocrystal of salicylic acid and phenylalanine amino acid. The first one reported as power phase of $\mathrm{H}_{2} \mathrm{Sal} \bullet \mathrm{Phe}$ with no report on pharmaceutical cosmetics $[18,19]$. Another cocrystal reported as zwitterions cocrystal. The preparations of salicylic acid are wildly prepared in a topical dosage form such as cream, gel, ointment and paste $[4,20,21]$. There is no report on the development of salicylic cocrystal as a topical preparation. Therefore, the main objective of this work was to synthesize the neutral cocrystal and to study the feasibility and produce chemical peeling cream from cocrystal ( $\mathrm{H}_{2} \mathrm{Sal} \bullet$ Phe).

\section{MATERIALS AND METHODS}

\section{Chemicals and reagents}

All the excipients used in this study were of analytical grade. Salicylic acid and phenylalanine were obtained from Sigma-Aldrich 
and used without purification. Jojoba oil, isopropyl myristate, castor oil, cyclomethicone (and) dimethicone cross polymer, vitamin E, glycerin, PEG 400, xanthan gum, Span 80 and Tween 60 were obtained from S. Tong Chemical Co., Ltd., Bangkok, Thailand. Glyceryl monostearate, white bee's wax, and cetostearyl alcohol were purchased from Namsiang, Bangkok, Thailand. All the excipients used in this study were of pharmaceutical or analytical grade.

\section{Synthesis of cocrystal $\mathrm{H}_{2}$ Sal•Phe}

In the typical procedure, pharmaceutical cocrystals $\left(\mathrm{H}_{2} \mathrm{Sal} \bullet \mathrm{Phe}\right)$ were synthesized by the solvent evaporation method $[10,11]$. Cocrystal $\left(\mathrm{H}_{2} \mathrm{Sal} \bullet \mathrm{Phe}\right)$ was synthesized by reacting salicylic acid with phenylalanine in the $1: 1$ mole ratios at $50{ }^{\circ} \mathrm{C}$ as tabulated in table 1 . The final $\mathrm{pH}$ was 2 . After a few days, the colorless crystals were obtained with a percent yield of 85 .

Table 1: The synthesis of cocrystal $\left(\mathrm{H}_{2} \mathrm{Sal} \bullet \mathrm{Phe}\right)$

\begin{tabular}{|c|c|c|c|c|c|}
\hline Starting materials & M. W. (g/mol) & Mole ratio & Temp. $\left({ }^{\circ} \mathrm{C}\right)$ & Solvent & Volume (ml) \\
\hline $\mathrm{H}_{2} \mathrm{Sal}$ & 138.12 & 1 & 50 & EtOH & 5 \\
\hline Phe & 165.19 & 1 & 50 & Water & 10 \\
\hline
\end{tabular}

\section{Single crystal X-ray structure determination}

X-ray diffraction studies were carried out at 296(2) K on an APEX2 CCD diffractometer equipped with graphite monochromated Mo K $\alpha$ radiation $(\lambda=0.71073 \AA)$. The SAINT program was used for data collection, cell refinement and data reduction. The SADABS program applied only cocrystal refinement [22]. The structures were solved by direct methods using Shelxs97 and the structured refined against $F^{2}$ for all reflections by full matrix methods in Shelx197. All nonhydrogen atoms were refined anisotropically and the hydrogen atoms were placed in geometric positions and refined as the riding model atoms with $\mathrm{C}-\mathrm{H}=0.93 \AA$ and $\mathrm{U}_{\text {iso }}(\mathrm{H})=1.2 \mathrm{U}_{\text {eq }}(\mathrm{C})$. Program Mercury and Diamond were used to demonstrate the fig. 2-3.

\section{Fourier transform infrared spectra (FT-IR)}

FT-IR was recorded on a Bruker OPUS 7. The FT-IR sample spectra measurements were prepared as potassium bromide $(\mathrm{KBr})$ discs in the region $4000-400 \mathrm{~cm}^{-1}$.

\section{Ultraviolet-visible spectra (UV-Vis)}

UV-Vis of starting materials and cocrystal dissolving in the ethanol was measured using the Shimadzu UV-1601 spectrophotometer over the range of 800 to $190 \mathrm{~nm}$.

\section{Preparation of chemical peeling cream from cocrystal $\mathrm{H}_{2}$ Sal॰Phe}

To adjust the formula to get the right cream, we investigated both the oil phase and the water phase. At the development process, we choose the oil phase which contains such as jojoba oil, isopropyl myristate, glyceryl monostearate, and the water phase which contains glycerin and tween. It produced quite a hard cream and not stable after freeze- thaw. After trial for cream preparation, we developed and found that the suitable way to produce cream containing the mixtures of jojoba oil, isopropyl myristate, castor oil, glyceryl monostearate cetostearyl alcohol, cyclomethicone (and) dimethicone crosspolymer, vitamin E, white bee's wax, glycerin, polyethylene glycol 400 (PEG 400), xanthan gum and sorbitan monostearate 80 (Span ${ }^{\circledR} 80$ ) and polysorbate 60 (Tween ${ }^{\circledR} 60$ ) as emulsifier.

The cocrystal $\left(\mathrm{H}_{2} \mathrm{Sal} \bullet \mathrm{Phe}\right)$ as an active ingredient which was dissolved in the water phase. Oil in water emulsion creams (control formulation and a formulation containing the $\mathrm{H}_{2} \mathrm{Sal} \bullet$ Phe) were formulated by the beaker method [23, 24]. Glyceryl monostearate, white bee's wax, and cetostearyl alcohol were dissolved in the oil phase (jojoba oil, isopropyl myristate, castor oil, cyclomethicone (and) dimethicone crosspolymer) and heat to $70 \pm 2^{\circ} \mathrm{C}$. Xanthan gum was slowly dispersed with continuous agitation in purified water until a clear solution was obtained. At the same time, the ingredients in the water phase (glycerin, PEG 400 and paraben concentrate) were dissolved in purified water and then heat to $75 \pm 2^{\circ} \mathrm{C}$. The emulsions were stabilized by Span 80 and Tween 60. After heating the cream was prepared by the addition of the aqueous phase to the oily phase with continuous agitation. Mixing was carried out by the mechanical mixer for $10 \mathrm{~min}$ until the complete aqueous phase was added. Finally, a few drops of vitamin E were added during this stirring time to the formulations and then cream was homogenized with a small homogenizer at $3000 \mathrm{rpm}$ for $10 \mathrm{~min}$. Control formulation was also prepared by the same above method but without $\mathrm{H}_{2} \mathrm{Sal} \bullet$ Phe (the active ingredient) and served as a control with compensating the amount of API by purified water. The pharmaceutical cocrystal $\left(\mathrm{H}_{2} \mathrm{Sal} \bullet \mathrm{Phe}\right)$ was varied from $0 \%$ (control formula) and up to $1 \% \mathrm{w} / \mathrm{w}$. The full list of the cream formulations was shown in table 2 . Finally, the finished product will be specified.

Table 2: Compositional formulations of chemical peeling cream from cocrystal $\left(\mathrm{H}_{2} \mathrm{Sal} \bullet \mathrm{Phe}\right)$

\begin{tabular}{|c|c|c|c|c|c|}
\hline \multirow[t]{2}{*}{ Ingredients (\%w/w) } & \multicolumn{5}{|c|}{ Formulation code } \\
\hline & F1 & F2 & F3 & F4 & F5 \\
\hline Cocrystal $\left(\mathrm{H}_{2} \mathrm{Sal} \bullet P h e\right)$ & 0.25 & 0.50 & 0.75 & 1.00 & - \\
\hline Jojoba oil & 1.20 & 1.20 & 1.20 & 1.20 & 1.20 \\
\hline Isopropyl myristate & 2.00 & 2.00 & 2.00 & 2.00 & 2.00 \\
\hline Castor oil & 1.20 & 1.20 & 1.20 & 1.20 & 1.20 \\
\hline Glycery monostearate & 1.00 & 1.00 & 1.00 & 1.00 & 1.00 \\
\hline Cetostearyl alcohol & 2.00 & 2.00 & 2.00 & 2.00 & 2.00 \\
\hline Cyclomethicone (and) dimethicone crosspolymer & 5.00 & 5.00 & 5.00 & 5.00 & 5.00 \\
\hline Vitamin E & 2.00 & 2.00 & 2.00 & 2.00 & 2.00 \\
\hline Sorbitan monostearate $80\left(\operatorname{Span}^{\circledR} 80\right)$ & 2.00 & 2.00 & 2.00 & 2.00 & 2.00 \\
\hline White bee's wax & 0.80 & 0.80 & 0.80 & 0.80 & 0.80 \\
\hline Paraben concentrate (methylparaben $10 \%$ and propylparaben $2 \%$ in propylene glycol) & 1.00 & 1.00 & 1.00 & 1.00 & 1.00 \\
\hline Glycerine & 1.00 & 1.00 & 1.00 & 1.00 & 1.00 \\
\hline PEG 400 & 1.00 & 1.00 & 1.00 & 1.00 & 1.00 \\
\hline Xanthan gum & 0.80 & 0.80 & 0.80 & 0.80 & 0.80 \\
\hline Polysorbate 60 (Tween ${ }^{\circledR} 60$ ) & 1.00 & 1.00 & 1.00 & 1.00 & 1.00 \\
\hline Purified water & 77.75 & 77.50 & 77.25 & 77.00 & 78.00 \\
\hline
\end{tabular}

\section{Appearance}

A cream containing cocrystal $\left(\mathrm{H}_{2} \mathrm{Sal} \bullet \mathrm{Phe}\right)$ and control (F1-F5) were examined organoleptically after freshly prepared and after the centrifugal test (odor, color, thickness, look, feel) and physically (creaming, sedimentation and phase separation). Type of emulsions was determined microscopically (see dye solubility test). The standard colors such as pure white, white, signal white, slightly 
yellow, off white, light gray and other from pantone paper will be used to the comparison of the cream description.

\section{Homogeneity}

Homogeneity of various formulations was tested by visual observation according the scale reported by a previous study [25] and was ranked as follows: $+++=$ Excellent, $++=$ Very Good, $+=$ Good, $-=$ Poor

The criterion of homogeneity and texture was assessed by pressing a small quantity of the formulated cream between thumb and index finger. The excellent cream show 1-non greasy, 2-quickly absorbed, 3-presence soft and smooth texture and 4-no defect of emulsion unstable such as creaming or cracking. Very good show only 1 point of defect, good is 2 point defect. The resulting cream show stiffness, grittiness or greasiness is fall in the poor assessment.

\section{pH measurement}

The $\mathrm{pH}$ of freshly prepared emulsions and emulsions kept at different storage conditions were determined by a digital $\mathrm{pH}$-meter (Metrohm, Switzerland). About 0.5 gram of cream was dissolved with purified water and adjust to $50 \mathrm{ml}$ volume. This $1 \%$ cream was asses the $\mathrm{pH}$ value $[23,26]$. The $\mathrm{pH}$ determinations were carried out in triplicate and the mean was recorded.

\section{Dye solubility test}

One drop of cream mixed with a water-soluble dye such as amaranth and observed under the microscope. If the continuous phase appears red, then it means that the emulsion is $\mathrm{o} / \mathrm{w}$ type. Again, if the scattered globules appear red and continuous phase colorless, then it is w/o type [21].

\section{Viscosity test}

In order to determine the viscosity values (in Pa.s), rheological measurements were performed using Brookfield DV III ultra V6.0 RV cone and plate rheometer (Brookfield Engineering Laboratories, Middleboro, Massachusetts) using spindle \#CPE40 at $25 \pm 0.5^{\circ} \mathrm{C}$. The measurements were carried out in triplicate at $25 \pm 2{ }^{\circ} \mathrm{C}$, the average values are presented.

\section{Spreadability}

Spreadability is a term expressed to denote the extent of the area to which the cream readily spreads on application to the skin. Spreadability test equipment made in house by adapted from previous reference $[26,27]$. The spreadability was expressed in terms of time in seconds taken by two slides to slip off from the cream, placed in between the slides, under a certain load. Lesser the time is taken for separation of the two slides, better the spreadability. Two glass slides of standard dimensions $(7.5 \times 2.5 \mathrm{~cm})$ were selected. The sample formulation $(1 \mathrm{~g})$ whose spreadability had to be determined was placed over one of the slides. The other slide was placed on top of the formulations was sandwiched between the two slides across the length of $5 \mathrm{~cm}$ along the slide. $100 \mathrm{~g}$ weight was placed upon the upper slide so that the formulation between the two slides was pressed uniformly to form a thin layer. The weight was removed and the excess of formulation adhering to the slides was scrapped off. One of the slides was fixed on which the formulation was placed. The second movable slide was placed over it, with one end tied to a string to which load could be applied by the help of a simple pulley and a pan. A $30 \mathrm{~g}$ weight was put on the pan and the time taken for the upper slide to travel the distance of $5.0 \mathrm{~cm}$ and separate away from the lower slide under the direction of the weight was noted. The spreadability was then calculated from the following formula:

$$
\text { Spreadability }=\frac{\mathrm{m} \times \mathrm{l}}{\mathrm{t}}
$$

Where $\mathrm{m}$ is a weight tied to the upper slide ( $30 \mathrm{~g}), \mathrm{l}$ is the length of a glass slide $(5 \mathrm{~cm})$ and $\mathrm{t}$ is time taken in seconds.

\section{Assay content of salicylic acid in a cream containing cocrystal ( $\mathrm{H}_{2}$ Sal•Phe)}

The content of salicylic acid in cream preparation was analyzed by HPLC according to a previous report [28]. Briefly, a Waters detector
(Waters, Milford, USA) was used for HPLC analysis. Cream samples were dissolved with mobile phase and filtered through $0.45 \mu \mathrm{m}$ nylon membrane filter. Chromatographic analysis was performed and processed with Empower v.2.0 software (Waters, Milford, USA). The chromatographic system was using a C18 column $(5 \mu \mathrm{m}, 250 \times$ $4.6 \mathrm{~mm}$ i.d.). The mobile phase consists of acetonitrile: $0.05 \%$ trifluoroacetic acid aqueous solution (30:70) and the flow rate was set at $1.0 \mathrm{ml} / \mathrm{min}$. The sample was injected $5 \mu \mathrm{L}$. The UV detector was set at $230 \mathrm{~nm}$.

\section{In vitro SPF test}

The photoprotective efficacy was assessed in vitro by determining the sun protection factor (SPF) value of the formulations, which was calculated from SPF analyzer (Optometrics LLC/SPF-290F, USA). Divide all each sample from containers into beakers, followed by continuous stirring until the homogeneous appeared. After that, the homogenous sample was divided into a few more beakers with the continuous stirring yield for homogeneous. After completion, labeling the sample and packed in a glass bottle, cover and avoid the light. Each formulation was spread $\left(2 \mathrm{mg} / \mathrm{cm}^{2}\right)$ over a PMMA (polymethyl methacrylate) plates $\left(70.7 \mathrm{~mm}^{2}\right)$ with a fingertip. The plate samples were then allowed to dry for $15 \mathrm{~min}$ protected from the light, and exposed to a xenon arc solar simulator. Measurements were made under the following laboratory conditions at $24.0 \pm 0,5{ }^{\circ} \mathrm{C}$ and $50-60 \%$ relative humidity. The measurement was performed by 9 different scanning spots on each sample at $2 \mathrm{~nm}$ interval between 290-400 nm. UVB protection efficacy as SPF, UVA protection efficacy as the Boot star rating and critical wavelength was recorded. As a blank reference representing $100 \%$ light transmission, an intact, not coated, PMMA plate was used [29]. All of the measurements were undertaken in triplicates.

\section{Stability test}

The stability of cream containing cocrystal $\left(\mathrm{H}_{2} \mathrm{Sal} \bullet \mathrm{Phe}\right)$ was performed in 3 conditions. After freshly prepare the cream, the $50 \mathrm{~g}$ product was filled in plastic LDPE tube and analyzed the stability following:

(1) Centrifugation tests: Centrifugal tests were performed for emulsions immediately after preparation. Those tests were repeated after $1 \mathrm{~d}, 7 \mathrm{~d}, 14 \mathrm{~d}, 21 \mathrm{~d}$, and $28 \mathrm{~d}$ and $60 \mathrm{~d}$ of preparation. They were performed at $5000 \mathrm{rpm}$ and $25^{\circ} \mathrm{C}$ for $10 \mathrm{~min}$ by placing $5 \mathrm{~g}$ of each sample in centrifugal tubes $[27,30,31]$.

(2) Freeze and thaw cycle: Freeze and thaw treatment of the cream emulsion was performed immediately after preparation. Samples $(20 \mathrm{~g})$ were stored at $4 \pm 2{ }^{\circ} \mathrm{C}$ for $48 \mathrm{~h}$. Then, samples were subsequently thawed at $40 \pm 2^{\circ} \mathrm{C}$ for $48 \mathrm{~h}$. This test was carried out in triplicate for each sample. The physical appearance of cream was observed after finished 6 cycles [31].

(3) Long-term stability study: The samples were carried out in a stability chamber. The storage condition was $30 \pm 2{ }^{\circ} \mathrm{C}$ and $75 \pm 5 \% \mathrm{RH}$ for 1, 3, 6 mo. Color, phase separation and liquefaction of emulsions were observed [32].

\section{Microbial limit test}

The microbial limit test included of aerobic plate count, the content of Pseudomonas aeruginosa (P. aeruginosa), Staphylococcus aureus (S. aureus), yeast and mold count was performed according to [33]. One gram of cream was dispersed in a $4 \mathrm{ml}$ sterile Ringer's solution containing $0.25 \%$ Tween ${ }^{\circledR} 80$. Six dilutions were made in the same dispersing vehicle, and $0.1 \mathrm{ml}$ was placed out on the appropriate solid medium using the surface viable method. The test was performed following:

(1) Aerobic plate count: aerobic plate counts were determined by inoculating $0.1 \mathrm{ml}$ of the homogenate sample onto triplicate sterile plates of pre-poured and dried Standard Method Agar. Then, the plates were incubated for $48 \mathrm{~h}$ at $35^{\circ} \mathrm{C}$. Duplicates of each dilution $(1 \mathrm{ml})$ of neutralized and non-neutralized samples were pour-plated using Standard Method Agar (Oxoid, Basingstoke, Hampshire, England) and incubated at $30{ }^{\circ} \mathrm{C}$ for $48 \mathrm{~h}$. Plates containing 25-250 colonies were counted and the average number of $\mathrm{CFU} / \mathrm{g}$ was calculated. 
(2) Pseudomonas aeruginosa count: P. aeruginosa were enumerated on Pseudomonas Agar Base (CM 559, Oxoid) supplemented with Fucidin, cephaloridine, and cetrimide, providing a selective medium for $\mathrm{P}$. aeruginosa. Colonies were counted after two days of incubation at $25^{\circ} \mathrm{C}$.

(3) Staphylococcus aureus: Population of S. aureus was determined by standard plating methods. Colonies of Staphylococcus were selected, gram-stained, and observed for oxidase and catalase reactions to confirm their presence. All microbial counts were transformed into logarithms of the number of colony-forming units $(\log 10 \mathrm{CFU} / \mathrm{g})$.

(4) Yeast and mold count: The method involved enumeration of colonies on the Sabouraud dextrose chloramphenicol agar medium. Enumeration was carried out as a pour plate, surface spread, or membrane filtration method. Microbiological tests were repeated for formulations at $25^{\circ} \mathrm{C}$ after $0,7,14,21$ and $28 \mathrm{~d}$ of preparation.

Emergent colonies were counted after the necessary incubation. All operations were carried out in duplicates.

\section{Cell viability of the fibroblast with $\left(\mathrm{H}_{2} \mathrm{Sal} \bullet \mathrm{Phe}\right)$}

This test was performed according to a previous study [34]. The human skin fibroblast cell line (BJ, ATCC: CRL-2522, VA, USA) and human skin keratinocyte cell line (HaCaT, CLS 300493, Eppelheim, Germany) diluted to $1 \times 10^{5}$ cells $\mathrm{ml}^{-1}$ in Eagle's Minimum Essential Medium (EMEM, Gibco, USA) for BJ and Dulbecco's Modified Eagle's Medium (DMEM, Gibco, USA) for HaCaT, respectively, were seeded into 96 well plates. Both the media were supplemented with $10 \%$ fetal bovine serum (FBS, Gibco, NY, USA), 50 units $\mathrm{ml}^{-1}$ of penicillin and 50 $\mu \mathrm{g} \mathrm{ml}-1$ of streptomycin and the plates were incubated at $37^{\circ} \mathrm{C}$ in $5 \%$ $\mathrm{CO}_{2}$. After $24 \mathrm{~h}$, the culture media in the plates were replaced with fresh media. The $0.05 \%$ cocrystal $\left(\mathrm{Phe} \bullet \mathrm{H}_{2} \mathrm{Sal}\right.$ in the fresh medium were added into the culture plate and non-treated cells served as controls. After $24 \mathrm{~h}$ incubation, 3-(4,5-dimethylthiazolyl-2-yl)diphenyltetrazolium bromide (MTT) assay was performed to evaluate the metabolic activity of treated and control cells. Briefly, the cells were treated with $100 \mu \mathrm{l}$ of fresh media along with $50 \mu \mathrm{l}$ of MTT solution $\left(5 \mathrm{mg} \mathrm{ml}^{-1}\right)$ and incubated at $37^{\circ} \mathrm{C}$ under $5 \% \mathrm{CO}_{2}$ for $4 \mathrm{~h}$. After removal of the MTT containing media and addition of $100 \mu \mathrm{l}$ of DMSO, the absorbance was determined by a microplate reader (Biohit 830, Biohit ${ }^{\circledR}$, Finland) at a wavelength of $570 \mathrm{~nm}$. The percentage of cell proliferation was calculated for 10 cell passage and compared to the respective controls.

\section{Patch test}

The skin irritation test was used to evaluate the skin irritation by the preparation cream to the intact skin. In this research, 10 women volunteers to apply the selected chemical peeling cream (formula F4) and compared them with other 10 women as a control that used chemical peeling cream without cocrystal $\left(\mathrm{H}_{2} \mathrm{Sal} \bullet \mathrm{Phe}\right)$ (formula F5). All volunteers were informed of objectives, test procedures, and possible adverse effects, and rewarded for their participation. These volunteers have the right to withdraw from the study at any time without penalty and consequence. The results of pass patch test showed that no edema or erythema occurred in all 20 volunteers within $48 \mathrm{~h}$. This experiment was approved by the ethical committee of the university.

\section{Product satisfaction}

In order to investigate the product satisfaction, we choose 10 normal skin women (as the same of the patch test group) to evaluate our product through a questionnaire after usage once a day until day 7 . The method for applying the cream was done with adaptation from [35]. Before testing, the volunteers washed their hands with tap water and dried them with paper towels for $5 \mathrm{~min}$. afterward, the volunteers squeeze about $1 \mathrm{~g}$ of cream from the tube which they gently rubbed onto the back of their hand with their index finger. This rubbing was done 10 times in a circular motion. The volunteers left the cream for $5 \mathrm{~min}$ and they used an assessment sheet to assess aspects of cream. Afterward, they used tap water to rinse off the area where the cream had been applied. The questionnaires consist of the evaluate of odor, color, appearance, spreadability after applied on skin, viscosity and brightening. The five-rating scale used a scale that ranged from 1 (very poor satisfied) to 5 (strongly satisfied). Additionally, the developed product was compared satisfaction with the commercial product by the blinded experiment.

\section{RESULTS AND DISCUSSION}

\section{Synthesis result, physical property and X-ray structure}

We successfully prepared the crystals of the 1:1 (salicylic acid: phenylalanine) mole ratio, with solvent evaporation $[10,11]$. The way of preparation is not different from the previous report, but we obtained single crystal instead of power phase $[16,18,19]$. This is to confirm that the solvent evaporation method can be broken and reformed under these conditions. As known, free $\mathrm{H}_{2} \mathrm{Sal}$ and Phe are the better solubilities in alcohol, ether and chloroform than water [36]. This cocrystal $\left(\mathrm{H}_{2} \mathrm{Sal} \bullet \mathrm{Phe}\right)$ was well dissolved in ethanol and dimethyl sulfoxide, but slightly soluble in acetone and hexane. ( $\left.\mathrm{H}_{2} \mathrm{Sal} \bullet \mathrm{Phe}\right)$ cocrystal morphology exhibits the long plate-like morphologies, as shown in fig. 1.

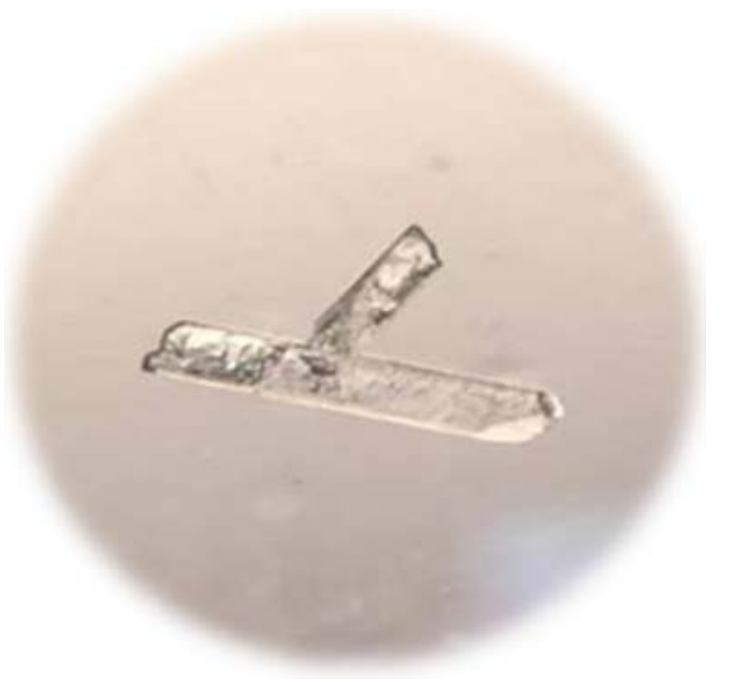

Fig. 1: Cocrystal $\left(\mathrm{H}_{2} \mathrm{Sal} \bullet \mathrm{Phe}\right)$

A single-crystal X-ray structural analysis shows that cocrystal crystalizes in the triclinic system with the space group $P-1$ as listed in table 3. The empirical formula of this cocrystal is $\mathrm{C}_{20} \mathrm{H}_{20} \mathrm{~N}_{4} \mathrm{O}_{12}$ which consists of two salicylic acid and two phenylalanine formulated as $\left(\mathrm{H}_{2} \mathrm{Sal} \bullet \mathrm{Phe}\right)_{2}$. This is to confirm that the asymmetric unit contains 2 molecules per unit cell.

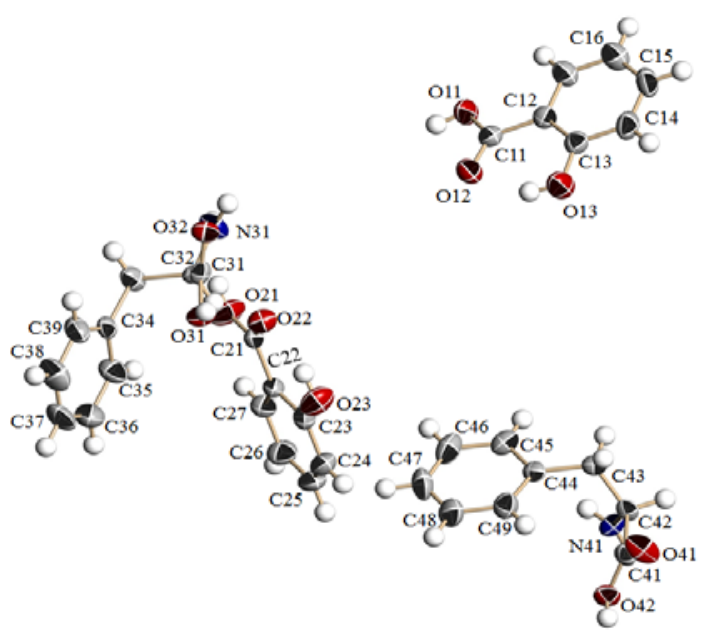

Fig. 2: Molecular structure of cocrystal $\left(\mathrm{H}_{2} \mathrm{Sal} \bullet \mathrm{Phe}\right)$ with the atomic numbering scheme 
Table 3: Crystal data and structure refinement for $\left(\mathrm{H}_{2} \mathrm{Sal} \bullet \mathrm{Phe}\right)$

\begin{tabular}{|c|c|}
\hline Parameter & Details \\
\hline CCDC & 1545143 \\
\hline Empirical formula & $\mathrm{C}_{20} \mathrm{H}_{20} \mathrm{~N}_{4} \mathrm{O}_{12}$ \\
\hline Formula weight & 508.40 \\
\hline Wavelength $(\AA)$ & 0.71073 \\
\hline Crystal system & Triclinic \\
\hline Space group & $P-1$ \\
\hline Unit cell & $\begin{array}{l}a=5.9141(8) \AA \AA, \alpha=83.939(5)^{\circ} \\
\mathrm{b}=15.912(3) \AA, \beta=80.427(5)^{\circ}\end{array}$ \\
\hline$V(\AA ̊ 3)$ & c $16.165(3) \AA, \gamma=86.846(5)^{\circ}$ \\
\hline $\begin{array}{l}V(\mathrm{~A} 3) \\
Z\end{array}$ & $\begin{array}{l}1490.5(4) \\
2\end{array}$ \\
\hline Density (calculated) (mg/m3) & 1.133 \\
\hline Absorption coefficient (mm-1) & 0.095 \\
\hline $\mathrm{F}(000)$ & 528 \\
\hline Theta range for data collection $\left({ }^{\circ}\right)$ & $1.28-25.19$ \\
\hline Independent reflections & $4335[\mathrm{R}(\mathrm{int})=0.0434]$ \\
\hline Completeness $\theta=25.10^{\circ}$ & $99.8 \%$ \\
\hline Absorption correction & SADABS \\
\hline Refinement method & Full-matrix least-squares on $F 2$ \\
\hline Data/restraints/parameters & $4335 / 0 / 397$ \\
\hline Goodness-of-fit on $F 2$ & 0.901 \\
\hline Final $R$ indices $[I>2 \sigma(I)]$ & $R_{1}=0.0654, \omega R_{2}=0.1623$ \\
\hline$R$ indices (all data) & $R_{1}=0.1707, \omega R_{2}=0.2350$ \\
\hline
\end{tabular}

Table 4: Selected bond lengths $[\AA ̊]$ and bond angles [ $\left[^{\circ}\right]$ of cocrystal $\left(\mathrm{H}_{2} \mathrm{Sal} \bullet \mathrm{Phe}\right)$

\begin{tabular}{llll}
\hline Atoms & Bond lengths $[\AA]$ & Atoms & Bond angles [ $\left.{ }^{\circ}\right]^{-}$ \\
\hline $\mathrm{O}(11)-\mathrm{C}(11)$ & $1.312(6)$ & $\mathrm{O}(12)-\mathrm{C}(11)-\mathrm{O}(11)$ & $122.8(5)$ \\
$\mathrm{O}(12)-\mathrm{C}(11)$ & $1.230(6)$ & $\mathrm{O}(11)-\mathrm{C}(11)-\mathrm{C}(12)$ & $114.5(5)$ \\
$\mathrm{O}(13)-\mathrm{C}(13)$ & $1.346(6)$ & $\mathrm{C}(13)-\mathrm{C}(12)-\mathrm{C}(17)$ & $119.1(5)$ \\
$\mathrm{O}(21)-\mathrm{C}(21)$ & $1.309(6)$ & $\mathrm{C}(13)-\mathrm{C}(14)-\mathrm{C}(15)$ & $120.0(6)$ \\
$\mathrm{O}(22)-\mathrm{C}(21)$ & $1.228(6)$ & $\mathrm{O}(22)-\mathrm{C}(21)-\mathrm{O}(21)$ & $121.5(5)$ \\
$\mathrm{O}(23)-\mathrm{C}(23)$ & $1.360(7)$ & $\mathrm{O}(22)-\mathrm{C}(21)-\mathrm{C}(22)$ & $122.6(5)$ \\
$\mathrm{O}(31)-\mathrm{C}(31)$ & $1.262(6)$ & $\mathrm{O}(21)-\mathrm{C}(21)-\mathrm{C}(22)$ & $115.9(5)$ \\
$\mathrm{O}(32)-\mathrm{C}(31)$ & $1.240(6)$ & $\mathrm{C}(23)-\mathrm{C}(22)-\mathrm{C}(21)$ & $120.3(5)$ \\
$\mathrm{O}(41)-\mathrm{C}(41)$ & $1.245(6)$ & $\mathrm{O}(23)-\mathrm{C}(23)-\mathrm{C}(24)$ & $117.1(5)$ \\
$\mathrm{O}(42)-\mathrm{C}(41)$ & $1.260(6)$ & $\mathrm{O}(32)-\mathrm{C}(31)-\mathrm{O}(31)$ & $126.0(5)$ \\
$\mathrm{N}(31)-\mathrm{C}(32)$ & $1.492(6)$ & $\mathrm{O}(31)-\mathrm{C}(31)-\mathrm{C}(32)-\mathrm{C}(32)$ & $119.2(5)$ \\
$\mathrm{N}(41)-\mathrm{C}(42)$ & $1.476(6)$ & $\mathrm{N}(31)-\mathrm{C}(32)-\mathrm{C}(31)$ & $114.8(5)$ \\
$\mathrm{C}(11)-\mathrm{C}(12)$ & $1.472(8)$ & $\mathrm{N}(31)-\mathrm{C}(32)-\mathrm{C}(33)$ & $108.8(4)$ \\
$\mathrm{C}(12)-\mathrm{C}(17)$ & $1.392(7)$ & & $107.8(4)$ \\
\hline
\end{tabular}

The x-ray parameter is in table 3. Selected bond lengths, bond angles, and torsion angles are listed in table 4 . The hydrogen bond and weak interactions are shown in table 5 . As seen in table 4 , the C$\mathrm{O}-\mathrm{H}$ of phenolic groups is longer than those of carboxylic groups such as $1.346(6) \AA$ vs. $1.312(6) \AA$, confirming the cocrystal stability
[10]. The packing diagram showed the inter-and intra-molecular interactions which are summarized in table 5. Undoubtedly, hydrogen bonding plays as important roles to form the building block units known as supramolecular synthons of motif, illustrated in fig. 3.

Table 5: Weak interaction of cocrystal $\left(\mathrm{H}_{2} \mathrm{Sal} \bullet \mathrm{Phe}\right)$

\begin{tabular}{|c|c|c|c|c|c|c|}
\hline Code & D-H & $d(D-H)$ & d(H. A) & $<$ DHA & d(D. A) & $\mathbf{A}$ \\
\hline (a) & 011-H11 & 0.820 & 1.818 & 169.68 & 2.629 & $042[-x+1,-y+1,-z+1]$ \\
\hline (b) & 013-H13A & 0.820 & 1.895 & 145.00 & 2.609 & 012 \\
\hline (c) & 021-H21 & 0.820 & 1.777 & 172.18 & 2.592 & $031[x-1, y, z]$ \\
\hline (d) & O23-H23A & 0.820 & 1.876 & 145.85 & 2.595 & 022 \\
\hline (e) & 031-H31 & 0.820 & 1.967 & 168.28 & 2.775 & $\mathrm{~N} 31[\mathrm{x}+1, \mathrm{y}, \mathrm{z}]$ \\
\hline (f) & N31-H31A & 0.860 & 2.293 & 131.70 & 2.937 & $032[-x+1,-y+2,-z+1]$ \\
\hline (g) & N31-H31B & 0.860 & 1.927 & 168.14 & 2.775 & $031[\mathrm{x}-1, \mathrm{y}, \mathrm{z}]$ \\
\hline (h) & N41-H41A & 0.860 & 1.962 & 162.43 & 2.555 & $012[\mathrm{x}, \mathrm{y}, \mathrm{z}]$ \\
\hline (i) & $\mathrm{N} 41-\mathrm{H} 41 \mathrm{~B}$ & 0.860 & 1.962 & 164.25 & 2.799 & $032[\mathrm{x}, \mathrm{y}-1, \mathrm{z}]$ \\
\hline
\end{tabular}

The packing diagram revealed that cocrystal consists of the intramolecular hydrogen bonding of Phe, intermolecular hydrogen bonding and pi-pi interactions of $\mathrm{H}_{2} \mathrm{Sal}$ and Phe rings as shown in fig. 3. It is clear that this cocrystal can be stable through the weak interaction between donor and acceptor atoms within a length of at least $3.00 \AA$.

\section{FT-IR spectra}

As seen in fig. 4 , the vibration spectra confirmed their components. The broad band over $2000 \mathrm{~cm}^{-1}$ indicated the weak interaction such as homosynthons which is in good agreements with interaction appeared in fig. 3. For the salicylic acid, the $\mathrm{O}-\mathrm{H}, \mathrm{C}-\mathrm{H}$ aromatic vibration bands are 
3239 and $3010 \mathrm{~cm}^{-1}$. The bands at $1657 \mathrm{~cm}^{-1}$ and $1612 \mathrm{~cm}^{-1}$ appear as intense bands corresponding to $\mathrm{C}=\mathrm{O}$ carboxylic vibration, and $\mathrm{C}=\mathrm{C}$ aromatic stretching bands. The spectra of phenylalanine from $3012 \mathrm{~cm}^{-1}$ and $2957 \mathrm{~cm}^{-1}$ are the combination stretching vibration bands of $\mathrm{O}-\mathrm{H}, \mathrm{N}-$
$\mathrm{H}, \mathrm{C}-\mathrm{H}$ aromatic and $\mathrm{C}-\mathrm{H}$ aliphatic functional groups. It also clearly confirmed the presence of $\mathrm{N}-\mathrm{H} \cdots \mathrm{O}$ and $\mathrm{O}-\mathrm{H} \cdots \mathrm{O}$ hydrogen bonds from the broadband spectra from $3012 \mathrm{~cm}^{-1}-2173 \mathrm{~cm}^{-1}$ which fit well with the weak interactions from $\mathrm{x}$-ray structure data.

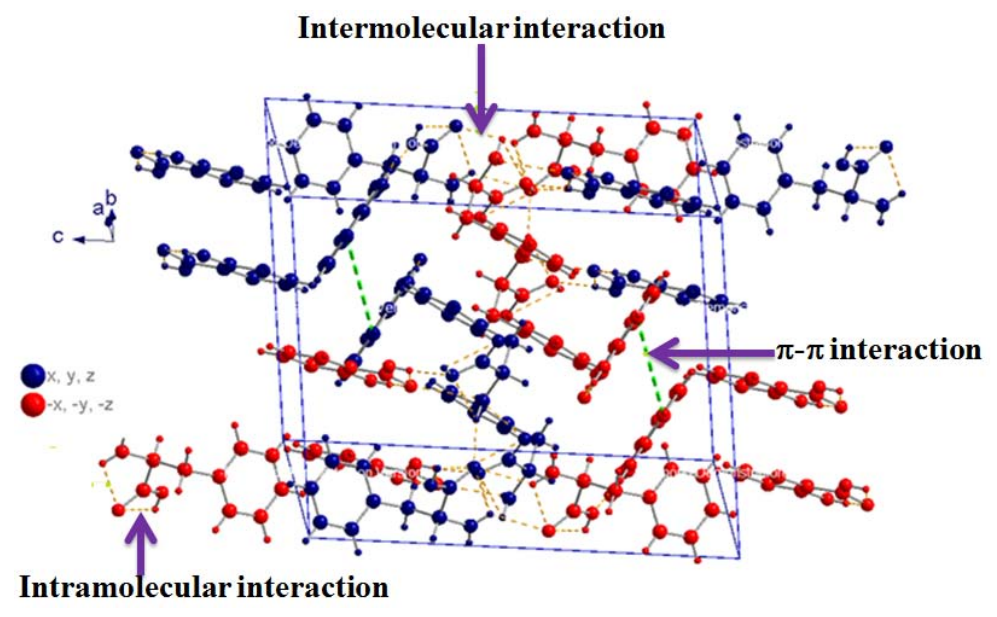

Fig. 3: The interactions of cocrystal contain inter-, intra-molecular and $\pi-\pi$ interactions
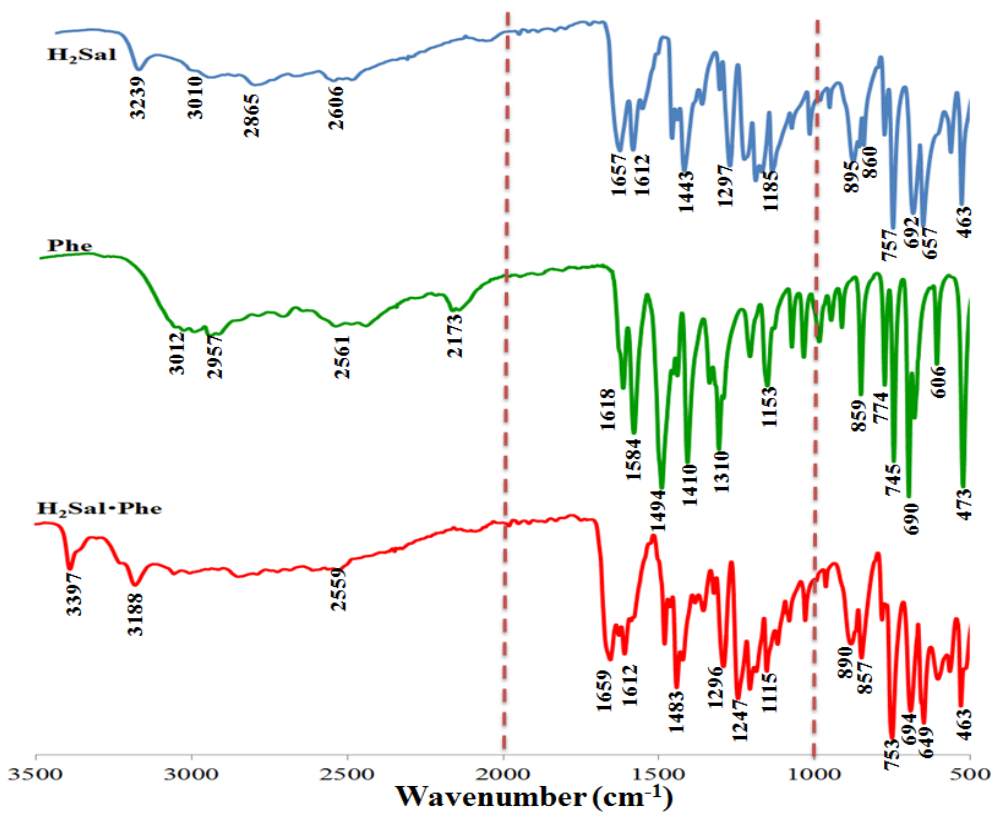

Fig. 4: The comparison FT-IR bands of salicylic, phenylalanine and cocrystal

According to the cocrystallization $\left(\mathrm{H}_{2} \mathrm{Sal} \bullet \mathrm{Phe}\right)$, the presence of stretching bands at $3397 \mathrm{~cm}^{-1}$ and $3188 \mathrm{~cm}^{-1}$ are strongly confirmed $\mathrm{O}-\mathrm{H}, \mathrm{N}-\mathrm{H}$ functional groups. Moreover, $\mathrm{N}-\mathrm{H} \cdots \mathrm{O}$ and $\mathrm{O}-$ $\mathrm{H} \cdots \mathrm{O}$ hydrogen bonds also appeared as the broadband spectra from $3397 \mathrm{~cm}^{-1}-2559 \mathrm{~cm}^{-1}$. As notice, the $\mathrm{C}=0$ bands of salicylic acid and phenylalanine are shifted to the lower or higher wavenumber by $2-28 \mathrm{~cm}^{-1}$ which suggested cocrystal of salicylic and phenylalanine [18]. By taking the previous work into account, our work shows no evidence of the strong bands at $1609 \mathrm{~cm}^{-1}$

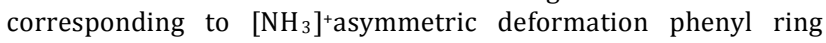
$[18,19]$. This is to indicate that our cocrystal does not consist of zwitterion characteristic but strongly confirm the neutral phenylalanine. In addition, the stretching $\mathrm{C}-\mathrm{O}$ spectra of the carboxylic group of salicylic acid and phenylalanine have bands at $1292 \mathrm{~cm}^{-1}$ and $1310 \mathrm{~cm}^{-1}$ respectively. During the cocrystallization, these bands appeared at $1296 \mathrm{~cm}^{-1}$ which indicated the carbonyl group participating in hydrogen bonding.
Formulation development of cosmetic creams containing pharmaceutical cocrystal $\left(\mathrm{H}_{2}\right.$ Sal॰Phe)

Cosmetic preparation containing $\left(\mathrm{H}_{2} \mathrm{Sal} \bullet \mathrm{Phe}\right)$ has developed as oil in water $(\mathrm{o} / \mathrm{w})$ creams because of spread easily and do not leave the skin greasy and sticky. In order to achieve this target, excipients formulation screening was necessary. The optimal formula should have the following characteristics: (i) it has previously been used as a clinical topical additive; (ii) it can comply with the product specifications as illustrated in table 6; and (iii) it passes the preliminary stability test by centrifugation test. In the present study, based on information in the Handbook of Pharmaceutical Excipients guidelines [37] and Handbook of Cosmetic Ingredients guidelines [38] on their use as additives for topical products, the formulations were developed. After trial and development of cream formulation, the full list of ingredients in the formulation as shown in table 2 with formulation codes are F1 to F4 with the reference F5 (without API). Cocrystal $\left(\mathrm{H}_{2} \mathrm{Sal} \bullet \mathrm{Phe}\right)$ was varied in the range of 0.25 to $1.0 \% \mathrm{w} / \mathrm{w}$. 


\section{Physical properties (appearance and homogeneity)}

The prepared formulations of chemical peeling cream from cocrystal $\left(\mathrm{H}_{2} \mathrm{Sal} \bullet \mathrm{Phe}\right)$ was inspected visually for color and homogeneity as shown in fig. 5 . The pharmaceutical examination has been investigated all of 5 formulations. The appearance of cream of each formulation is not much different which is white, soft, smooth cream with a characteristic odor. The different concentration of $\left(\mathrm{H}_{2} \mathrm{Sal} \bullet \mathrm{Phe}\right)$ show slightly color, texture and viscosity of the products. The findings revealed that the freshly prepared creams were pale yellow, soft yellowish-white, yellow, white and yellowish-white for F1, F2, F3, F4 and F5, respectively. Little changes in the color of all formulations may occur from the difference of cocrystal content in the formula. All formulations show excellent of homogeneity. The details of physical properties were shown in table 7 .

From the formulations, creams are developed by adjusting the amount of the substance in the formulation between $0-1 \%$ to find the appropriate amount on the purposes of a skin peeling effect and skin lightening. The substance formulation codes are F1 to F4 with the reference F5 as shown in table 6. Our preparation is based on the product specifications as illustrated in table 6 .

\section{The pH determinations}

The $1 \%(\mathrm{w} / \mathrm{w})$ of all formulations $\mathrm{F} 1-\mathrm{F} 5$ was in the $\mathrm{pH}$ value range of skin, according to table 7 . As seen, $\mathrm{F} 4$ shows nearly $\mathrm{pH}$ neutral which appropriate for the application of this cream on the skin surface [39].

\section{Dye solubility test}

Emulsion type (dye solubility), according to the results in table 7 , every formulation are oil in water emulsions. That means our product facilitates the absorption of water-insoluble compounds comparing to their oily solution preparations (e. g. cream) as shown in fig. 6.

\section{Viscosity}

Viscosity is the most important parameter in the evaluation as it governs the many properties of the formulation such as spreadability, pourability of the product from the container. The rheological behavior of the formulations was assessed by analysis of apparent viscosity, flow curve and hysteresis area. The apparent viscosity of cream formulation F1-F5 was found to be 625, 634, 643, 639 and $627 \mathrm{~Pa} \cdot$ s, respectively (table 7). Statistical analysis of the viscosity showed that they were not significantly different. The rheological behavior of the samples is shown as a shear-thinning system. As confirmed by the appearance of the plot of viscosity vs. shear rate, the creams exhibited thixotropic behavior, which is a desirable characteristic for topically applied products. In sum, the viscosity of F3 and F4 are quite higher than the others.

\section{Spreadability}

The cream base should spread easily without too much drag and should not produce greater friction in the rubbing process. The therapeutic efficacy of a formulation also depends on its spreading value. The results of spreadability are summarized in table 7 . The values of spreadability indicate that the cream is easily spreadable by a small amount of shear. The results of spreadability were found to $16.30,15.59,14.60,15.18$, and $17.32 \mathrm{~g} \cdot \mathrm{cm} / \mathrm{sec}$ of the formulation F1 to F5, respectively. All formulations were not significantly differenced because cream base and ingredient are the same. Emollients used in the studied formulations were chosen according to their ability to properly spread when applied on skin, covering more area and protecting more skin tissue, and also according to their sensory properties, which should be pleasant to the user, such as the capability of the formulation to cause a dry and velvety feeling when applied. These characteristics can be found in volatile silicones so that the formulas were added cyclomethicone and dimethicone crosspolymer. The low value of spreadability of the cream indicates the lesser work required to spread the cream over the skin, which means formulation easily spreadable by applying a small amount of shear [40].

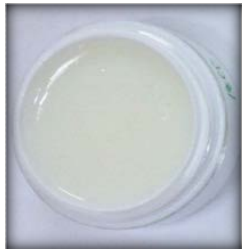

F1

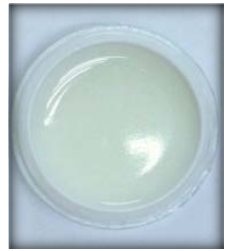

F2

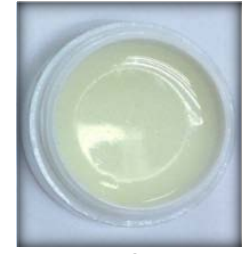

F3

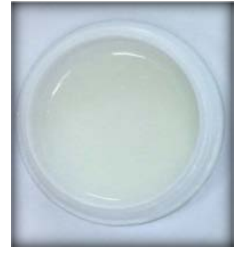

F4

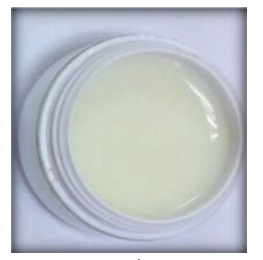

F5

Fig. 5: The finished creams F1 to F5

Table 6: Product specifications of cocrystal $\mathrm{Phe} \bullet \mathrm{H}_{2} \mathrm{Sal}$ cream cocrystal $\left(\mathrm{H}_{2} \mathrm{Sal} \bullet \mathrm{Phe}\right)$

\begin{tabular}{ll}
\hline Test & Specification \\
\hline Appearance & White, soft and smooth cream with a characteristic odor \\
pH & $4.0-6.0$ \\
Homogeneity & Excellent \\
Viscosity (Pa.s) & $500-1,000$ \\
Microbial limit test & Conform Thai FDA regulation \\
\hline
\end{tabular}

Table 7: Physical characterization of a cream containing cocrystal $\left(\mathrm{H}_{2} \mathrm{Sal} \bullet \mathrm{Phe}\right)$ with control

\begin{tabular}{|c|c|c|c|c|c|}
\hline \multirow[t]{2}{*}{ Test parameter } & \multicolumn{5}{|c|}{ Formulation code } \\
\hline & F1 & F2 & F3 & F4 & F5 \\
\hline Appearance & \multicolumn{5}{|c|}{ Soft, smooth cream with a characteristic odor. } \\
\hline Color & Pale yellow & Soft yellowish white & Yellow & White & Yellowish white \\
\hline $\mathrm{pH}$ & $4.82 \pm 0.02$ & $4.98 \pm 0.02$ & $5.10 \pm 0.05$ & $5.23 \pm 0.10$ & $4.80 \pm 0.03$ \\
\hline Homogeneity & +++ & +++ & +++ & +++ & +++ \\
\hline Viscosity $(\mathrm{Pa} \cdot \mathrm{s})$ & $625 \pm 12$ & $634 \pm 21$ & $643 \pm 15$ & $639 \pm 25$ & $627 \pm 12$ \\
\hline Spreadability (g/sec) & $16.30 \pm 0.02$ & $15.59 \pm 0.01$ & $14.60 \pm 0.05$ & $15.18 \pm 0.02$ & $17.32 \pm 0.26$ \\
\hline Emulsion type (dye solubility) & $\mathrm{o} / \mathrm{w}$ & $\mathrm{o} / \mathrm{w}$ & $\mathrm{o} / \mathrm{w}$ & $\mathrm{o} / \mathrm{w}$ & $\mathrm{o} / \mathrm{w}$ \\
\hline
\end{tabular}

* mean $\pm \mathrm{SD}=$ Standard Deviation from the mean, $\mathrm{n}=6$ 


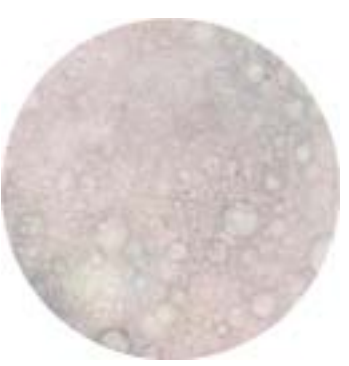

F1

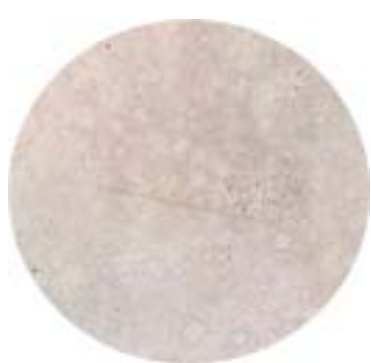

F4

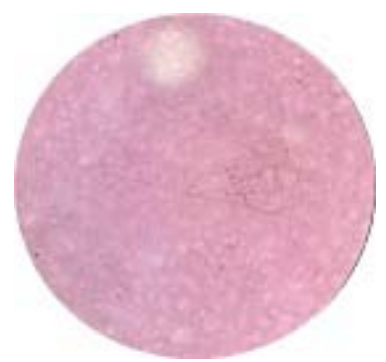

F5

Fig. 6: Dye solubility test shows only F1, F3 and F5 (control)

\section{Evaluation of the sun protection factor}

Sun protection factor (SPF) value is an indicator evaluating UVB protection efficacy of sunscreen product. The alternative method by in vitro assessment is less expensive and more efficient than in vivo assay by using human volunteers. As known, the SPF is a quantitative measurement of the effectiveness of a sunscreen formulation. Although cream containing $\left(\mathrm{H}_{2} \mathrm{Sal} \bullet \mathrm{Phe}\right)$ does not add sun protection ingredients, we observed the properties of sun protector when the formulation added cocrystal active substance. Fig. 7 shows the absorbance pattern of a cream containing cocrystal $\left(\mathrm{H}_{2} \mathrm{Sal} \bullet \mathrm{Phe}\right)$. The results reveal that these formulations are quite low SPF value $(<5$, see table 8) because we didn't add the sunscreen protection ingredients. According to reference [41], high SPF values are more difficult to measure. A high SPF normally leads to a greater uncertainty also in the final in vivo result, due to the biological variations of the volunteers.

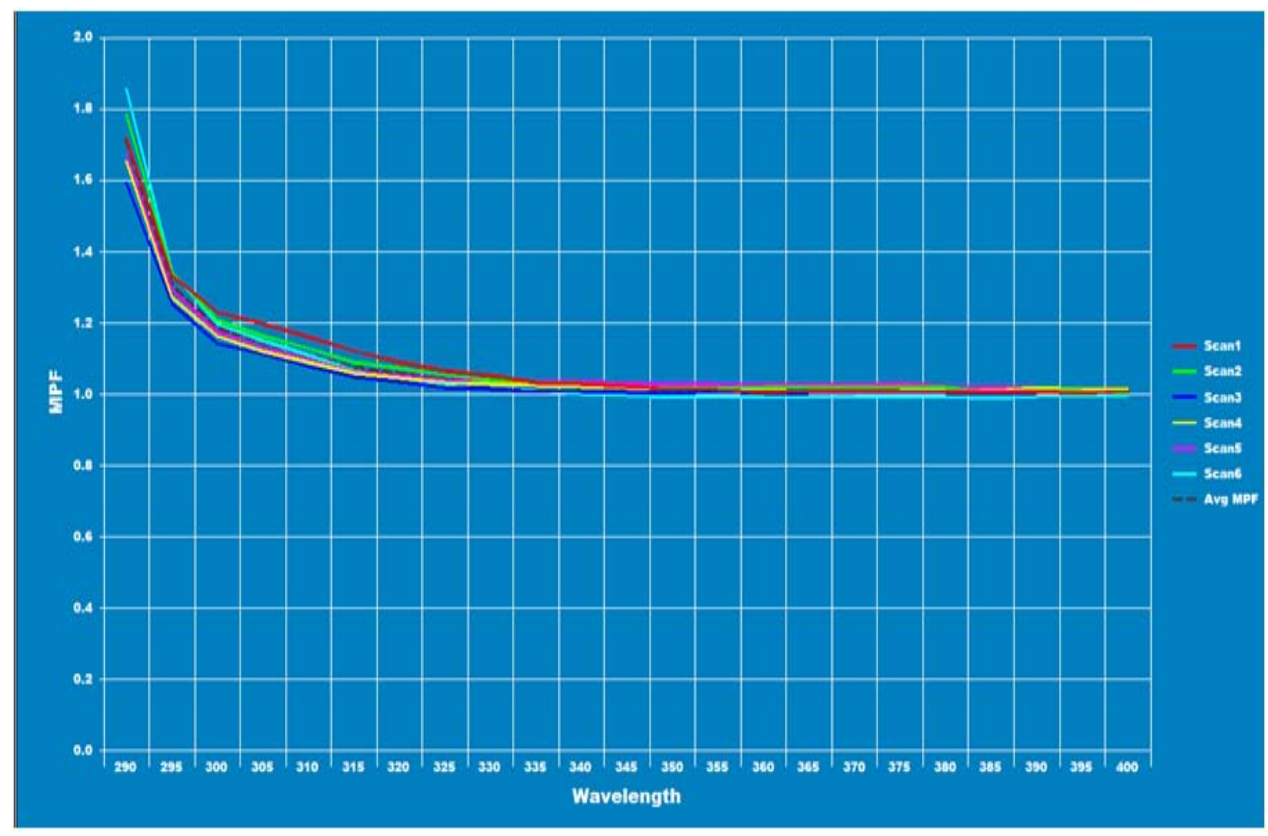

Fig. 7: The absorbance pattern of cream containing cocrystal $\left(\mathrm{H}_{2} \mathrm{Sal} \bullet \mathrm{Phe}\right)$

Table 8: SPF study parameters of the formulations

\begin{tabular}{llllll}
\hline Test & F1 & F2 & F3 & F4 & \\
\hline SPF & $4.5 \pm 0.2$ & $4.5 \pm 0.2$ & $4.3 \pm 0.1$ & $4.6 \pm 0.2$ & $4.2 \pm 0.2$ \\
\hline
\end{tabular}

* mean $\pm \mathrm{SD}=$ Standard Deviation from the mean, $\mathrm{n}=6$

\section{Stability study}

The purpose of the accelerated (centrifugation, freeze-thaw and $\left.40^{\circ} \mathrm{C} / 75 \% \mathrm{RH}\right)$ and long-term stability $\left(30^{\circ} \mathrm{C} / 75 \% \mathrm{RH}\right)$ testing our cream is to ensure that our product meets the standard along with the shelf-life of the products and should be provided on at least three primary batches of the API. After formulation samples have undergone heat and physical stress at several periods of time, their resulting of colors was not change from initial of all formulations.

After analyzing the results from table 9, the evaluation showed that the all formulation presented higher consistency of appearance (visual observation) for the centrifugation, accelerated test and freeze-thaw cycles conditions, and at the long-term for 3 mo. Liquefaction and phase separation was not observed in the cream preparation. The results indicated adequate stability, mainly in the high-temperature condition and good compatibility with the LDPE plastic packaging. The $\mathrm{pH}$ value presented very low variations of the initial specifications of this product in all conditions. Apparent viscosity from the accelerated stability study is described in table 9 . All products showed viscosity values were decreased only storage at $40^{\circ} \mathrm{C} / 75 \% \mathrm{RH}$. The difference in the viscosity value variation in high temperature caused by stiffening agents in the formulation were melts. The assay content of salicylic acid in $\left(\mathrm{H}_{2} \mathrm{Sal} \bullet \mathrm{Phe}\right)$ was found 
that within the range of $95-102 \%$ labeled amount. This result confirms that the chemical stability of salicylic acid in the cocrystal form was stable after stress condition and long-term condition. In conclude according to table 9, all formulations were found to be stable with no sign of change in physical appearance, characteristic, and drug content.

Table 9: Stability study parameters of the formulations

\begin{tabular}{|c|c|c|c|c|c|c|c|}
\hline \multirow[t]{2}{*}{ Formulation } & \multirow[t]{2}{*}{ Conditions } & \multicolumn{6}{|c|}{ Parameter evaluated } \\
\hline & & Color & Liquefaction & Phase separation & pH & $\begin{array}{l}\text { Viscosity } \\
\text { (Pa.s) }\end{array}$ & $\begin{array}{l}\text { Salicylic acid } \\
\text { content }\end{array}$ \\
\hline \multirow[t]{4}{*}{ F1 } & Centrifugation (28 d) & - & - & - & $5.03 \pm 0.02$ & NA & NA \\
\hline & Freeze-Thaw ( 6 cycles) & - & - & - & $5.02 \pm 0.04$ & $624 \pm 13$ & NA \\
\hline & $30^{\circ} \mathrm{C} / 75 \% \mathrm{RH}(3 \mathrm{mo})$ & - & - & - & $5.03 \pm 0.02$ & $642 \pm 12$ & $96.28 \pm 0.23$ \\
\hline & $40^{\circ} \mathrm{C} / 75 \% \mathrm{RH}(3 \mathrm{mo})$ & - & - & - & $5.04 \pm 0.01$ & $572 \pm 32$ & $95.13 \pm 0.92$ \\
\hline \multirow[t]{4}{*}{$\mathrm{F} 2$} & Centrifugation (28 d) & - & - & - & $5.00 \pm 0.02$ & NA & NA \\
\hline & Freeze-Thaw ( 6 cycles) & - & - & - & $5.04 \pm 0.01$ & $622 \pm 12$ & NA \\
\hline & $30^{\circ} \mathrm{C} / 75 \% \mathrm{RH}(3 \mathrm{mo})$ & - & - & - & $5.02 \pm 0.05$ & $653 \pm 13$ & $97.91 \pm 0.45$ \\
\hline & $40^{\circ} \mathrm{C} / 75 \% \mathrm{RH}(3 \mathrm{mo})$ & - & - & - & $5.01 \pm 0.05$ & $562 \pm 23$ & $99.15 \pm 1.28$ \\
\hline \multirow[t]{4}{*}{ F3 } & Centrifugation (28 d) & - & - & - & $5.04 \pm 0.02$ & NA & NA \\
\hline & Freeze-Thaw ( 6 cycles) & - & - & - & $5.04 \pm 0.02$ & $641 \pm 12$ & NA \\
\hline & $30^{\circ} \mathrm{C} / 75 \% \mathrm{RH}(3 \mathrm{mo})$ & - & - & - & $5.04 \pm 0.04$ & $642 \pm 22$ & $102.53 \pm 1.16$ \\
\hline & $40^{\circ} \mathrm{C} / 75 \% \mathrm{RH}(3 \mathrm{mo})$ & - & - & - & $5.01 \pm 0.07$ & $571 \pm 25$ & $98.74 \pm 1.25$ \\
\hline \multirow[t]{4}{*}{ F4 } & Centrifugation (28 d) & - & - & - & $5.01 \pm 0.02$ & NA & NA \\
\hline & Freeze-Thaw ( 6 cycles) & - & - & - & $5.04 \pm 0.03$ & $644 \pm 42$ & NA \\
\hline & $30^{\circ} \mathrm{C} / 75 \% \mathrm{RH}(3 \mathrm{mo})$ & - & - & - & $5.09 \pm 0.04$ & $642 \pm 22$ & $101.16 \pm 1.97$ \\
\hline & $40^{\circ} \mathrm{C} / 75 \% \mathrm{RH}(3 \mathrm{mo})$ & - & - & - & $5.00 \pm 0.04$ & $594 \pm 32$ & $101.54 \pm 2.58$ \\
\hline \multirow[t]{4}{*}{ F5 } & Centrifugation (28 d) & - & - & - & $5.03 \pm 0.02$ & NA & NA \\
\hline & Freeze-Thaw ( 6 cycles) & - & - & - & $5.02 \pm 0.04$ & $585 \pm 11$ & NA \\
\hline & $30^{\circ} \mathrm{C} / 75 \% \mathrm{RH}(3 \mathrm{mo})$ & - & - & - & $5.20 \pm 0.12$ & $585 \pm 22$ & $96.86 \pm 0.12$ \\
\hline & $40^{\circ} \mathrm{C} / 75 \% \mathrm{RH}(3 \mathrm{mo})$ & - & - & - & $4.83 \pm 0.20$ & $542 \pm 32$ & $98.55 \pm 2.33$ \\
\hline
\end{tabular}

-= no change, $\mathrm{NA}=$ not applicable, ${ }^{*}$ mean $\pm \mathrm{SD}=$ Standard Deviation from the mean, $\mathrm{n}=6$

\section{Microbial limit test}

This test is designed to estimate the number of viable aerobic microorganisms present in a product and defines designated microbial species for products from the raw materials stage to a final manufactured product. Microbial limits testing for cosmetic and pharmaceutical products is an important part and to ensure the microbial safety of our cream for the consumer, maintain the quality of the product, and confirm the hygienic and the high-quality handling. We carry out routine microbiological of our finished product. Microbial limits testing for pharmaceutical products is an important part. The results showed no antibacterial effect with the evidence of low values of viable aerobic microorganisms and microbial species, as stated in table 10. Aerobic bacteria, Pseudomonas aeruginosa, Staphylococcus Aureus, yeast and molds are considered the main potential pathogens in cosmetic products. The chemical peeling cream results showed that results are under the Thai FDA regulation. The results showed no antibacterial effect with the evidence of low values of viable aerobic microorganisms and microbial species as stated in table 10.

Table 10: Microbial load of aerobic plate count, P. spp, S. aureus and yeast and molds count of the formulations F4 (three replicates batch)

\begin{tabular}{|c|c|c|c|}
\hline \multirow[t]{2}{*}{ Parameters } & \multicolumn{3}{|c|}{ Days of storage at room temperature } \\
\hline & $\mathbf{0}$ & 14 & 28 \\
\hline \multicolumn{4}{|c|}{ Aerobic plate count } \\
\hline F1 & $2.00 \pm 0.22$ & $2.32 \pm 0.31$ & $2.38 \pm 0.25$ \\
\hline F2 & $2.01 \pm 0.24$ & $2.24 \pm 0.25$ & $2.29 \pm 0.20$ \\
\hline F3 & $3.04 \pm 0.25$ & $3.16 \pm 0.23$ & $3.33 \pm 0.18$ \\
\hline F4 & $2.02 \pm 0.30$ & $2.42 \pm 0.33$ & $2.51 \pm 0.30$ \\
\hline F5 & $1.06 \pm 0.21$ & $1.56 \pm 0.25$ & $1.84 \pm 0.12$ \\
\hline \multicolumn{4}{|l|}{ P. spp } \\
\hline F1 & $<1$ & $<1$ & $<1$ \\
\hline F2 & $<1$ & $<1$ & $<1$ \\
\hline F3 & $<1$ & $<1$ & $<1$ \\
\hline F4 & $<1$ & $<1$ & $<1$ \\
\hline F5 & $<1$ & $<1$ & $<1$ \\
\hline \multicolumn{4}{|l|}{ S. aureus } \\
\hline F1 & $<1$ & $<1$ & $<1$ \\
\hline $\mathrm{F} 2$ & $<1$ & $<1$ & $<1$ \\
\hline F3 & $<1$ & $<1$ & $<1$ \\
\hline $\mathrm{F} 4$ & $<1$ & $<1$ & $<1$ \\
\hline F5 & $<1$ & $<1$ & $<1$ \\
\hline \multicolumn{4}{|c|}{ Yeast and molds } \\
\hline F1 & - & - & - \\
\hline F2 & - & - & - \\
\hline F3 & - & - & - \\
\hline $\mathrm{F} 4$ & - & - & - \\
\hline F5 & - & - & - \\
\hline
\end{tabular}

-= No coliform detected, ${ }^{*}$ mean \pm SD $=$ Standard Deviation from the mean, $\mathrm{n}=3$ 


\section{Cell viability}

Cytotoxicity test is designed to determine the toxicity to cells either qualitatively or quantitatively. The viability of BJ and HaCaT cell lines incubated with the $\mathrm{H}_{2} \mathrm{Sal} \bullet \mathrm{Phe}$ at a concentration of $0.5 \%$ were assessed on the toxicity of the cocrystal. More than $80 \%$ of survival was recorded for the cocrystal $\left(\mathrm{H}_{2} \mathrm{Sal} \bullet \mathrm{Phe}\right)$.

\section{Patch test}

The skin irritation test was used to evaluate the skin irritation by the preparation cream to the intact skin. In this research, 10 women to apply the chemical peeling cream (F4) and compared them with other 10 women as a control that used chemical peeling cream without cocrystal $\left(\mathrm{H}_{2} \mathrm{Sal} \bullet \mathrm{Phe}\right)(\mathrm{F} 5)$. The results showed that no edema or erythema occurred in all 20 volunteers within $48 \mathrm{~h}$.

\section{Product satisfaction}

After 10 woman volunteers maintain using the product for $14 \mathrm{~d}$, the questionnaire was an inquiry. Customer satisfaction listed in table 11 is a marketing term that measures how products or services supplied by a company meet or surpass a customer's expectation. In this work, we choose 10 normal skin women (the same patch test group) to evaluate our product through a questionnaire after usage.

Overall, the satisfaction levels of our product are high in each category. The questionnaire indicated that the most satisfactory of using our $\mathrm{F} 4$ cream was with $10 \%$ excellent, $80 \%$ very good, and $10 \%$ good. In sum, we took F4 for further investigation, such as patch test and product satisfaction.

Table 11: Product satisfaction of F4

\begin{tabular}{lllll}
\hline Parameter satification & \% & & \\
\cline { 2 - 5 } & Excellent (5) & Very good (4) & Good (3) & Poor (2) \\
\hline Ordor & 20 & 70 & 10 & 0 \\
Colour & 20 & 80 & 0 & 0 \\
Appearance & 70 & 10 & 20 & 0 \\
Spreadiblilty after applied & 30 & 40 & 20 & 0 \\
Viscosity after applied & 30 & 60 & 10 & 0 \\
Brightening after applied & 30 & 30 & 10 & 0 \\
Total satisfications & 10 & 80 & 10 & 0 \\
\hline
\end{tabular}

\section{CONCLUSION}

The goals of this study were to prepare new pharmaceutical cocrystal between salicylic acid and phenylalanine and aiming this cocrystal as an active ingredient to formulate the new chemical peeling or whitening cosmetics. We also successfully achieved these goals. The results both from the structure determination by single-crystal X-ray diffraction and from infrared spectra confirm cocrystal with no zwitterion on phenylalanine as the previous report. and strongly confirm cocrystal. The inter-, intra-molecular interactions and $\pi-\pi$ interactions stabilized the structure. Cocrystal $\left(\mathrm{H}_{2} \mathrm{Sal} \bullet \mathrm{Phe}\right)$ was formulated in chemical peeling cream by conventional beaker method with general ingredients for pharmaceutical or cosmetic cream. From the pharmaceutical investigation such as appearances, physical and chemical properties. The chemical peeling cream containing cocrystal $\left(\mathrm{H}_{2} \mathrm{Sal} \bullet \mathrm{Phe}\right)$ has shown the promising results which are both safe and efficacious peeling agent. Cocrystal $\left(\mathrm{H}_{2} \mathrm{Sal} \bullet \mathrm{Phe}\right)$ cream can be used as an alternative choice in whitening skin after performing the clinical study.

\section{ACKNOWLEDGMENT}

We gratefully acknowledge Thaksin University via the Research and Development Institute Thaksin University (RDITSU) with the grants No.0006543 and No.0098059.

\section{SUPPLEMENTARY DATA}

CCDC 1545143 contains the supplementary crystallographic data for cocrystal $\left(\mathrm{H}_{2} \mathrm{Sal} \bullet \mathrm{Phe}\right)$. These data can be obtained free of charge via http://www. ccdc. cam. ac. uk/conts/retrieving. html, or from the Cambridge Crystallographic Data Centre, 12 Union Road, Cambridge CB2 1EZ, UK; fax: (+44) 1223-336-033; or e-mail: deposit@ccdc.cam.ac.uk.

\section{AUTHORS CONTRIBUTIONS}

Experimental design, execution, data generation, support to draft manuscript design, data interpretation and corrections were done by Hirihattaya Phetmung and Somchai Sawatdee. The design, guidance for work and manuscript review was done by Hirihattaya Phetmung. All authors were revised and review the manuscript.

\section{CONFLICT OF INTERESTS}

\section{Declared none}

\section{REFERENCES}

1. Doaa S Sayed, Amira A Abdel-Motaleb. Salicylic acid versus lactic acid peeling in mild and moderate acne vulgaris. Alpe Adria Microbiol J 2012;10:341-54.
2. Raman K Madan, Jacob Levitt. A review of toxicity from topical salicylic acid preparations. J Am Acad Dermatol 2013;70:788-92.

3. Alex N Manin, Alexander P Voronin, Nikolay G Manin, Mikhail V Vener, Anastasia V Shishkina, Anatoly S Lermontov, et al. Salicylamide cocrystals: screening, crystal structure, sublimation thermodynamics, dissolution, and solid-state DFT calculations. J Phys Chem B 2014;118:6803-14.

4. Tesleem Arif. Salicylic acid as a peeling agent: a comprehensive review. Clin Cosmet Investig Dermatol 2015;8:455-61.

5. Jaishree Sharad. Glycolic acid peel therapy-a current review. Clin Cosmet Investig Dermatol 2013;6:281-8.

6. Franziska Stefanie Ihlefeldt, Fredrik Bjarte Pettersen, Aidan Von Bonin, Malgorzata Zawadzka, Carl Henrik Gorbitz. The polymorphs of l-phenylalanine. Angew Chem Int Ed Engl 2014;53:13600-4.

7. Anaelle Tilborg, Bernadette Norberg, Johan Wouters. Pharmaceutical salts and cocrystals involving amino acids: a brief structural overview of the state-of-art. Eur J Med Chem 2014;74:411-26.

8. Marina Landau. Chemical peels. Clin Dermatol 2008;26:200-8.

9. Marta I Rendon, Diane S Berson, Joel L Cohen, Wendy E Roberts, Isaac Starker, Beatrice Wang. Evidence and considerations in the application of chemical peels in skin disorders and aesthetic resurfacing. J Clin Aesthet Dermatol 2010;3:32-43.

10. William Jones, Samuel Motherwell, Andrew V Trask. Pharmaceutical cocrystals: an emerging approach to physical property enhancement. MRS Bull 2006;31:875-9.

11. Srinivasulu Aitipamula, Annie BH Wong, Pui Shan Chow, Reginald BH Tan. Pharmaceutical cocrystals of ethenzamide: structural, solubility and dissolution studies. Cryst Eng Comm 2012;14:8515-24.

12. MA Elbagerma, HGM Edwards, $\mathrm{T}$ Munshi, Ian J Scowen. Identification of a new co-crystal of salicylic acid and benzamide of pharmaceutical relevance. Anal Bioanal Chem 2010;397:137-46.

13. Tomislav Friscic, William Jones. Benefits of cocrystallization in pharmaceutical materials science: an update. J Pharm Pharmacol 2010;62:1547-59.

14. Anna Karagianni, Maria Malamatari, Kyriakos Kachrimanis. Pharmaceutical cocrystals: new solid-phase modification approaches for the formulation of APIs. Pharmaceutics 2018;10:18.

15. Sulbha R Fukte, Milind P Wagh, Shilpi Rawat. Conformer selection: an important tool in cocrystal formation. Int J Pharm Pharm Sci 2014;6:9-14. 
16. Zhengzheng Zhou, Hok Man Chan, Herman HY Sung, Henry HY Tong, Ying Zheng. Identification of new cocrystal systems with stoichiometric diversity of salicylic acid using thermal methods. Pharm Res 2016;33:1030-9.

17. Pei-Wen Hsieh, Ibrahim A Aljuffali, Chia-Lang Fang, Shu-Hao Chang, Jia-You Fang. Hydroquinone-salicylic acid conjugates as novel anti-melasma actives show superior skin targeting compared to the parent drugs. J Dermatol Sci 2014;76:12031.

18. Mohamed A Elbagerma, Howell GM Edwards, Tariq Allaudin Munshi, Michael D Hargreaves, Pavel Matousek, Ian J Scowen. Characterization of new cocrystals by raman spectroscopy, powder x-ray diffraction, differential scanning calorimetry, and transmission raman spectroscopy. Cryst Growth Des 2010;10:2360-71.

19. Mohamed Atiega Elbagerma, Howell GM Edwards, Adel Imhemed Alajtal, Ian Ja Scowen. Identification and structural studies of the salicylic acid DL-phenylalanine cocrystal. Am J Chem Mat Sci 2017;4:49-58.

20. Nitha Vincent, Ramya Devi D, BN Vedha Hari. Development and optimization of emollient gel loaded with salicylic acid for the effective treatment of psoriasis. Res J Pharm Biol Chem Sci 2014;5:1299-311.

21. Barkat Ali Khan, Naveed Akhtar, Haji Muhammad Shoaib Khan, Khalid Waseem, Tariq Mahmood, Akhtar Rasul, et al. Basic of pharmaceutical emulsions: a review. Afr J Pharm Pharmacol 2011;5:2715-25.

22. George M Sheldrick. Crystal structure refinement with SHELXL. Acta Cryst 2015:C71:3-8.

23. EE Soje, Jameel Muazu, Shadrack Madu. Formulation and in vitro assessment of cream prepared from Allium cepa L., Bulb. Asian J Pharma Sci Technol 2016;6:1-5.

24. Avish D Maru, Swaroop R Lahoti. Formulation and evaluation of moisturizing cream containing sunflower wax. Int J Pharm Pharm Sci 2018;10:54-9.

25. Ali Heyam Saad, Shehab Naglaa Ahmed, El-ahaj Babiker Mohamed. Formulation and evaluation of herbal cream from Ziziphus Spina leaves extract. Int Res J Pharm 2013;4:44-8.

26. Teelavath Mangilal, KSK Rao Patnaik, R Shyam Sunder, S Anuradha Bai. Preparation and evaluation of polyherbal antiaging cream by using different synthesis polymers. Int J Herb Med 2017;5:92-5.

27. Shailendra Kumar Sah, Ashutosh Badola, Sayantan Mukhopadhyay. Development and evaluation of tioconazole loaded emulgel. Int J Appl Pharm 2017;9:83-90.

28. Jose Luiz Neves de Aguiar, Katia Christina Leandro, Shirley de Mello Pereira Abrantes, Andre Luis Mazzei Albert. Development of a new analytical method for determination of acetylsalicylic and salicylic acids in tablets by reversed-phase liquid chromatography. Braz J Pharm Sci 2009;45:723-7.

29. Mingwiman S, Werawatganone P, Muangsiri W. Correlation of in vitro SPF values from two laboratories. Thai J Pharm Sci 2016;40:65-8

30. Slim Smaoui, Hajer Ben Hlima, Raoudha Jarraya, Nozha Grati Kamoun, Raoudha Ellouze, Mohamed Damak. Cosmetic emulsion from virgin olive oil: formulation and bio-physical evaluation. Afr J Biotechnol 2012;11:9664-71.

31. Jadhav CM, Kate VK, Payghan SA. Stability study of griseofulvin in non-aqueous microemulsion system. Asian J Biomed Pharm Sci 2014;4:79-83.

32. Priyanka R Kapare, Kishan L Jadhav, Divya V Khairmode, Shradha D Sawant, Akash S Mali. Development and evaluation of cosmeceutical cream for acne vulgaris. Int J Adv Community Med 2018;1:50-3.

33. Slim Smaoui, Hajer Ben Hlima, Ines Ben Chobba, Adel Kadri. Development and stability studies of sunscreen cream formulations containing tree photo-protective filters. Arab J Chem 2017;10:S1216-22.

34. Anongtip SA, Somchai Sawatdee, Narubodee Phadoongsombut, Wilaiporn Buatong, Titpawan Nakpeng, Rutthapol Sritharadol, et al. Quantitative analysis of povidone-iodine thin films X-ray photoelectron spectroscopy and their physicochemical properties. Acta Pharm 2017;67:169-86.

35. Yutaka Inoue, Kensuke Suzuki, Rikimaru Maeda, Arisa Shimura, Isumu Murata. Evaluation of formulation properties and skin penetration in the same additive-containing formulation. Results Pharma Sci 2104;4:42-9.

36. Fredrik L Nordstro, Åke C Rasmuson. Solubility and melting properties of salicylic acid. J Chem Eng Data 2006;51:1668-71.

37. Raymond C Rowe, Paul J Sheskey, Marian E Quinn. Handbook of pharmaceutical excipients. $6^{\text {th }}$ edition. Pharmaceutical Press. USA; 2009.

38. Dweck A. Handbook of cosmetic ingredients-their use, safety and toxicology, $3^{\text {rd }}$ edition. Dweck Data; 2011.

39. Ehrhardt Proksch. pH in nature, humans and skin. J Dermatol 2018:45:1044-52.

40. Ravi Shankar, Babita Sarang, Ramesh Gupta, Kamla Pathak. Formulation and characterization of polyherbal cream for skin manifestations. JAASP 2016;1:360-66.

41. Medical Device Division. Notification of the Food and Drug Administration; 2010. p. 1-13.

42. Alireza Firooz, Bardia Sadr, Shahab Babakoohi, Maryam SarrafYazdy, Ferial Fanian, Ali Kazerouni-Timsar, et al. Variation of biophysical parameters of the skin with age, gender, and body region. Sci World J 2012;1-5. http://dx.doi.org/10.1100/ 2012/386936 